NBER WORKING PAPER SERIES

\title{
HOW IMPORTANT ARE MINIMUM WAGE INCREASES IN INCREASING THE WAGES OF MINIMUM WAGE WORKERS?
}

\author{
Jeffrey Clemens \\ Michael R. Strain \\ Working Paper 29824 \\ http://www.nber.org/papers/w29824
NATIONAL BUREAU OF ECONOMIC RESEARCH
1050 Massachusetts Avenue
Cambridge, MA 02138
March 2022

Clemens: University of California at San Diego, Economics Department, 9500 Gilman Drive \#0508, La Jolla, CA 92093, USA. Telephone: 1-509-570-2690. E-mail: clemens.jeffrey @ gmail.com. Strain: American Enterprise Institute, 1789 Massachusetts Avenue, NW, Washington, DC 20036, USA. Telephone: 1-202-862-5800. E-mail: michael.strain@ @aei.org. We thank Duncan Hobbs for excellent research assistance. The views expressed herein are those of the authors and do not necessarily reflect the views of the National Bureau of Economic Research.

NBER working papers are circulated for discussion and comment purposes. They have not been peerreviewed or been subject to the review by the NBER Board of Directors that accompanies official NBER publications.

(C) 2022 by Jeffrey Clemens and Michael R. Strain. All rights reserved. Short sections of text, not to exceed two paragraphs, may be quoted without explicit permission provided that full credit, including (C) notice, is given to the source. 
How Important are Minimum Wage Increases in Increasing the Wages of Minimum Wage

Workers?

Jeffrey Clemens and Michael R. Strain

NBER Working Paper No. 29824

March 2022

JEL No. J23,J3,J58

\begin{abstract}
Popular discussion commonly presumes an outsized role for minimum wage increases as a driver of wage increases for minimum wage workers. In this paper, we investigate the accuracy of this presumption using data from the earnings studies of the Current Population Survey (CPS). CPS wage and earnings data enable us to assess the fraction of minimum wage workers who receive a raise within 12 months of their initial appearance as a minimum wage worker. On average from 2010 to 2019, we find that roughly 75 percent of minimum wage workers who remain employed experience a wage increase within 12 months. This fraction is higher during the later years of the sample, when the labor market has been strong, than in the earlier years. The fraction of minimum wage workers receiving wage increases is moderately higher when states enact minimum wage increases than when they do not. We also find that the fraction of minimum wage workers receiving wage increases is correlated with several measures of labor market tightness. Finally, wage gains are quite commonly associated with industry and/or occupation switches. This highlights the importance of career progression for the growth of earnings among entry-level workers. The vast majority of the wage gains realized by minimum wage workers thus appear to be driven by career progression and increases in labor demand. Minimum wage increases play a modest role as a driver of earnings trajectories beyond shaping the initial, typically short-lived, minimum wage job itself.
\end{abstract}

\author{
Jeffrey Clemens \\ Department of Economics \\ University of California, San Diego \\ 9500 Gilman Drive \#0508 \\ La Jolla, CA 92093 \\ and NBER \\ jeffclemens@ucsd.edu \\ Michael R. Strain \\ American Enterprise Institute \\ 1789 Massachusetts Avenue, NW \\ Washington, DC 20036 \\ and IZA \\ michael.strain@aei.org
}




\section{Section I: Introduction}

What drives wage trajectories among individuals at the very low end of the wage distribution? The determinants of wage growth have become a subject of considerable interest and controversy. For example, these issues hold the distinction of being the focus of David Card's 2022 Presidential Address to the American Economic Association (Card, 2022). And economists and commentators alike are increasingly debating the relative importance of competitive market forces, employer power, and institutions in wage setting.

The traditional economic view holds that wage trajectories are a product of market forces. In this view, people's wages rise either because their skills improve or because the dynamics of supply and demand increase the price employers pay for workers who possess those skills. An institutionalist view holds, to the contrary, that wages are driven by bargaining power. In this view, wages at the bottom of the wage distribution will only rise through institutional interventions, such as a government-mandated increase in the minimum wage.

Our purpose in this paper is to examine the relative importance of the minimum wage in increasing the wages of minimum wage workers. Our analysis uses the Outgoing Rotation Groups of the Current Population Survey (CPS-ORG) for years extending from 2010 to 2019. We use the subset of the Current Population Survey (CPS) in which individuals are asked about their wages in addition to being asked about their employment. CPS respondents are asked these questions twice, and the relevant interviews occur 12 months apart. For those who are employed in both surveys, the CPS's wage data thus reveal whether they experienced wage growth over a full calendar year.

Our analysis yields several findings of interest. Our first finding is that wage growth is the norm among minimum wage workers who persist in their employment. We define minimum 
wage workers in our baseline sample as individuals with wages within 50 cents of the effective minimum wage when they are first interviewed about their earnings. Among individuals in this sample, more than 70 percent of those employed 12 months later are employed at a higher wage. On average, the wages of minimum wage workers rose by $\$ 1.39$, with the increase conditional on realizing an increase averaging just over $\$ 2.05$. The wage increases we observe, which occur over 12-month horizons, suggest that a very small fraction of individuals can plausibly be described as "career minimum wage workers."

Moreover, we find qualitatively similar likelihoods of wage growth among workers who live in states that increased their minimum wages and among those who do not. Around 71 percent of minimum wage workers in states that did not increase their minimum wage at any point in the 2013-2018 period got a raise in any given year, compared to around 79 percent of minimum wage workers in states that did increase their minimum wage. Wage increases for minimum wage workers is the norm in both groups of states.

Our initial finding is consistent with past work on the prevalence of "minimum wage careers." In a widely cited study of wage growth experienced by minimum wage workers, Smith and Vavrichek (1992) found, using data from the 1984 panel of the Survey of Income and Program Participation (SIPP), that just over 60 percent of minimum wage workers experienced wage growth if employed one year later. In an update of Smith and Vavrichek's work, Long (1999) found a similar prevalence of wage gains using data from the 1992 panel of the SIPP. Even and McPherson (2003, 2004) generated quite similar findings using data from the CPSORG. Even and McPherson's analysis suggests that the prevalence of wage gains among minimum wage workers has been quite stable, rising moderately from 1979 through 2002.

We next explore the correlates of wage growth among individuals who were minimum 
wage workers at baseline. We find that wage growth is positively correlated with several broad classes of factors. We find particularly strong correlations between wage growth and variables that describe whether an individual has changed industries or occupations. This suggests that wage growth is strongly predicted by progression in minimum wage workers' careers. We also find correlations between wage growth and several proxies for overall macroeconomic conditions. These correlations suggest that increases in overall demand for labor generate wage gains. Finally, we find that wage growth is positively correlated with institutional variables including indicators for both the enactment of minimum wage increases and for whether the individual is a member of, or is covered by, a union. Taken together, we thus find that a broad set of factors predict wage growth, including the progression of an individual's career, overall economic conditions, and institutional forces.

We push farther in an effort to quantify the role of minimum wage increases relative to other factors by estimating a linear probability model of the likelihood of a minimum wage worker getting a raise between CPS ORG interviews. For workers who were employed in both outgoing rotations, we find that living in a state that increased its minimum wage in between interviews is associated with a 13.8 percentage point increase in the probability of getting a raise. For the 12-month periods during which a minimum wage increase went into effect, this estimate implies a 21 percent increase in the probability of receiving a wage, as the baseline mean in states that never increased their minimum wages is 65.8 percent. In states that implemented a minimum wage increase at least once during our sample, minimum wage increases account for roughly 8 percent of the wage increases realized by minimum wage workers across our full sample period.

The remainder of this paper proceeds as follows. In Section II we describe our data 
sources. In section III we present our analysis of the prevalence and correlates of wage gains realized by minimum wage workers. In section IV we briefly conclude.

\section{Section II: Data Sources}

In this section, we discuss the data sources and variables we use in the analysis. These include wage data, macroeconomic data, data on occupational and industry mobility, and data on labor market institutions. We conclude this section with a brief discussion of summary statistics.

\section{Wage Data and the CPS ORG}

Our analysis of the wage growth experienced by minimum wage workers draws on a variety of sources. Our wage data come from the Current Population Survey (CPS). We use several wage-related variables asked of individuals in two out of the eight interviews in which they participate in the CPS. The relevant interviews, during which respondents are asked a more detailed set of questions than during their more basic interviews, take place during the last month of each of two four-month waves of a respondent's participation. Because new households enter the survey each month, and one-fourth of the households are in an outgoing rotation each month, these interviews are known as the Outgoing Rotation Group (ORG) interviews.

Several variables are relevant for estimating an individual's wage rate and for gauging the quality of the underlying data. The first key piece of information is an indicator for whether the respondent is paid on an hourly basis. When they are, the respondent is asked for their hourly wage rate. When they are not, hourly wage rates can be inferred by dividing the 
individual's usual weekly earnings by their usual weekly hours. While all of the relevant information is subject to respondent reporting error, the potential for error is greater when the hourly wage must be inferred from earnings and hours data because the hourly wage itself is not reported directly. Further, a non-trivial fraction of respondents elect not to report their earnings information when asked. The wage rates for these individuals can thus only be imputed. To mitigate the impact of these errors, we focus on individuals who have baseline wage rates quite close to the minimum wage, who are paid by the hour, and who do not have imputed wage rates.

\section{Labor Market Institutions}

Our analysis considers two variables that describe labor market institutions. The first is a simple indicator, taken directly from the ORG files, for whether an individual is a union member or is covered by a union or employee association contract. The second describes states' effective minimum wage rates. ${ }^{2}$ We gather data on minimum wages from a variety of sources including the Department of Labor, Vaghul and Zipperer (2021), and the National Conference of State Legislators. When we encountered conflicts across sources, we cross-checked the data using specific pieces of state legislation as well as contemporaneous news articles describing states policy changes. We compiled the relevant data in Clemens, Hobbs, and Strain (2018), which presents a brief analysis of the lags with which this period's minimum wage changes have been implemented. These data also supported the analyses in Clemens and Strain (2017, 2018, 2021), which complement the current paper through short- and medium-run analyses of the effects of

\footnotetext{
${ }^{2}$ The effective minimum wage rate is the larger of the federal minimum wage rate and the applicable state minimum wage rate.
} 
this period's minimum wage changes on employment.

\section{Macroeconomic variables}

Our analysis considers the relationship between wage increase and several proxies for macroeconomic conditions. Specifically, we consider indicators of the performance of statelevel housing markets, state aggregate income, and labor markets. We proxy for variations in the recovery of the housing market using a statewide median house price index from the Federal Housing Finance Agency (FHFA). We proxy for aggregate economic performance using data on aggregate state income per capita from the Bureau of Economic Analysis (BEA). Finally, we proxy for variations in broader labor market developments using employment among skill groups not directly affected by the minimum wage.

In our analysis of the relationship between macroeconomic variables and wage growth, we consider two time horizons. More specifically, we relate wage growth across ORG interviews to "short" and "medium-run" changes in macroeconomic conditions. Our "short-run" variables capture 1-year changes in each of our macroeconomic variables, while our "mediumrun" variables capture 3-year changes in our macroeconomic variables.

\section{Skill Accumulation}

We also consider variables that describe individual-level skill accumulation. Our proxies for skill accumulation are limited to the standard observables used in Mincerian human capital regressions, namely proxies for education and experience. Our education variable is an indicator 
for whether the individual's self-reported years of education increased between their first and second ORG interview. Our experience variable captures the fraction of interview months between ORG interviews during which the individual reported being employed. A key limitation of these variables is that we observe very little variation in combined accumulation of education and experience. The reason for this is that we observe minimum wage workers over the course of a single year, during which most are either working or in school. Accumulation of experience and education thus tend to be highly collinear with one another.

\section{Occupation and Industry Switches}

The final set of variables we consider describe whether an individual switched industries or occupations between ORG interviews. We construct separate variables to capture whether an individual shifted across 1-digit, 2-digit, or 3-digit occupation or industry codes. If an individual is missing occupation or industry codes for either ORG interview, we treat these variables as missing.

\section{Summary Statistics}

Table 2 presents summary statistics for our samples of individuals ages 16-64 whose baseline wage rates were within $\$ 0.50$ of the minimum wage in effect at the time of their first ORG interview. We divide the sample into four groups based on two criteria. The first is the year of the first interview and the second describes whether the individual initially resided in a state in which the minimum wage was increased at some point during our sample. The sample is conditioned on individuals being employed once again at the time of their second ORG 
interview.

The first row of table 2 presents means for our primary variable of interest, which is an indicator for whether an individual had a higher wage at the time of their second interview than at the time of their first interview. Across the four groups, the means range from 0.66 to 0.79 . Between two-thirds and three-quarters of individuals who are employed at the minimum wage thus tend to be earning a higher wage if they are employed twelve months later. This probability was greater over the sample for which the baseline interview occurred between 2013 and 2018 than in the sample first interviewed between 2010 and 2012. This is consistent with a role for the relatively robust stage of the expansion that followed the Great Recession. Second, we see that wage gains were moderately more common for minimum wage workers in states that enacted minimum wage changes than those in states that did not.

The remaining rows in the table are of interest for gauging the magnitudes of other factors potentially influencing wage gains. The summary statistics reveal several facts of potential interest. First, changes across occupation and industry groupings are quite common for individuals who are initially minimum wage workers. Second, union membership is relatively uncommon for this group, ranging between 1.5 and 5.5 percent across the columns. Union membership is particularly uncommon for individuals in states that enacted no minimum wage increases during our analysis sample. Finally, our set of macroeconomic covariates exhibit the means and variations one would expect based on the economic expansion associated with the time period we analyze. 


\section{Section III: Analysis of the Frequency of Wage Gains and Their Correlates}

Our analysis proceeds in four straightforward steps. We first document facts that describe the extent to which minimum wage jobs are transitory. Second, we present data on the correlates of wage growth among individuals who were minimum wage workers at baseline. Third, we differentiate between states and time periods during which minimum wage increases did or did not go into effect, which yields additional insight into the relevance of states’ minimum wage policies for wage growth at the bottom of the distribution. Finally, we round out our picture of wage growth's correlates by presenting similar data on wage growth among individuals whose baseline hourly wage rates were moderately higher than their states' effective minimum wages.

How Permanent or Transitory Is Minimum Wage Employment?

The first descriptive statistics we present connect our analysis to past work on the relevance of "minimum wage careers." Figure 1 reports annual time series on the fraction of individuals who are employed at the minimum wage at the time of their first ORG interview and are employed at a higher wage at the time of their second ORG interview. We present this series for the full sample of individuals who earned near the minimum wage at baseline as well as for our primary analysis sample, which restricts the broader sample to those who remained employed at the time of their second ORG interview.

The data reveal that these fractions are quite stable over time. Since the early 2000s, roughly 75 percent of individuals employed in minimum wage jobs during their first ORG interview are, conditional on remaining employed, earning higher wage rates at the time of their 
second ORG interview. Without conditioning on employment, the fraction averages closer to fifty-five percent. These facts have two implications. First, the data place a strong upper bound on the relevance of "minimum wage careers." The twelve-month time horizon we can analyze in the ORG is quite far from being a career. Even over this relatively short horizon, only 25 percent of those employed at the time of both interviews remain employed in minimum wage jobs at the time of their second interview. Second, the fact this fraction has been quite stable over time suggests the operation of the labor market, at least with respect to the wage gains it delivers to low-wage workers, has not changed substantially over the last several decades.

What Are the Correlates of Wage Gains at the Bottom of the Wage Distribution?

Table 3 presents correlations between four sets of covariates and the wage gains realized by minimum wage workers. That is, each row presents a simple bivariate correlation coefficient describing the relationship between the size of the wage gain an individual experienced and the variable named in the row. As in table 2, the sample consists of individuals employed at near the minimum wage in their first ORG interview and also employed at the time of their second ORG interview. The sets of covariates include labor market institutional variables, proxies for individual-level skill accumulation, proxies for short and medium run macroeconomic performance, and variables that capture shifts in an individual's industry or occupation.

Among the covariates we consider, the only group for which there is a weak correlation with wage growth are the variables that describe changes in observable correlates of skill, namely experience and education. This likely reflects the fact that our analysis can only capture the relationship between wages and relatively short-run changes in these variables. Importantly, 
those who have an increase in their reported years of schooling will mechanically have had less time in the labor market to accumulate experience. Similarly, those who report being employed in all three of the interview months between their ORG interviews are among those least likely to be investing in schooling.

Variables that proxy for career progression, namely changes in occupation or industry, are quite strongly correlated with wage gains. ${ }^{3}$ A shift across 2-digit occupation codes, for example, quite strongly predicts an increase in wages, as does a shift across 2-digit industry codes. Although these correlations are purely descriptive, it is worth noting these findings are consistent with past work on the importance of improved job matches at the early stages of individuals' careers (Topel and Ward, 1992). ${ }^{4}$ These facts suggest an important role for early career progression from entry-level jobs towards jobs that require more advanced education, training, and experience.

Several of our proxies for macroeconomic conditions are also quite strongly predictive of wage gains. Notably, the correlation between macroeconomic conditions and wage growth is stronger over the "medium" run than over the "short" run. Specifically, we find that 3-year changes in the house price index and in aggregate income per capita are strongly predictive of wage gains. The strength of these correlations are more modest for 1-year changes. In general,

\footnotetext{
${ }^{3}$ Recent work by Liu (Forthcoming; 2022) has investigated the effects of minimum wage increases on the probability that workers change jobs. Liu (Forthcoming) finds that minimum wage increases reduce the occupational mobility of young and less educated workers, which can have implications for their future wage growth. Liu (2022) finds that relatively large minimum wage increase, in particular, have a substantial negative impact on upward occupational mobility.

${ }^{4}$ These facts can also be connected to empirical research on the long-run effects graduating during a recession, which limits the range of opportunities a worker can quickly explore (Kahn, 2010; Oreopoulus, von Wachter, and Heisz, 2012). They also connect to canonical theory that highlights the importance of job matches for understanding patterns of tenure and turnover (Jovanovic, 1979).
} 
these correlations are consistent with an important role for "demand" as a determinant of wage growth. The relevance of lags is consistent with findings from Stansbury and Summers (2017) as well as Strain (2018).

Finally, we observe strong correlations between our institutional covariates and wage growth. Although union membership is quite rare among minimum wage workers, it is a strong predictor of increases in their wage. The enactment of a minimum wage increase during the months between an individual's ORG interviews is also a strong predictor of wage gains.

\section{Wage Gains Comparing States that Did and Did Not Enact Minimum Wage Increases}

In this section, we take a further look at the relationship between wage gains and minimum wage increases. Specifically, we present summary statistics for which we divide the sample to separate states and time periods during which minimum wage increases went into effect vs. states and time periods during which the minimum wage did not change.

Table 4 presents statistics regarding wage increases and changes in key labor market indicators between outgoing rotations for individuals living in states that did or did not have a minimum wage increase in the 12 months between their ORG interviews. Averaging across the early and late portions of the sample, the share of workers receiving a wage increase between rotations is roughly 13 percentage points higher (roughly 19 percent on a baseline average of 67 percent) in states where the minimum wage increased between outgoing rotations. ${ }^{5}$ This fact

\footnotetext{
${ }^{5}$ It is worth dwelling briefly on the fact that fewer than 100 percent of minimum wage workers in states that increased their minimum wage rates experience wage gains. This may be related to several phenomena. First, some of the workers in our samples may be in jobs that are exempt from the minimum wage. Second, as analyzed by Clemens and Strain (2020), some workers may fail to enjoy wage gains due to evasion or avoidance of minimum wage regulation. Third, the absence of measured wage gains may, in some instances, result from measurement error.
} 
suggests minimum wage increases are responsible for a moderate increase in the probability an individual receives a wage increase. Specifically, when a state's minimum wage rises, it appears to be responsible for roughly 15 percent of the wage gains experienced by minimum wage workers. Across our sample period, minimum wage increases account for roughly 8 percent of the wage increases realized by minimum wage workers who lived in states that increased their minimum wages at least once over the course of the decade. Twenty-three states did not enact a minimum wage increase during our sample period.

To further probe the relationship between minimum wage increases and wage gains we next present summary statistics for workers who were employed in both of their outgoing rotation group interviews and reported earning 5 to 7 dollars more per hour than the effective minimum wage in their state of residence. The wages these workers receive should be influenced by changing macroeconomic conditions or changes in job mobility, but not directly affected by minimum wage changes. Therefore, examining how the probability of wage gains shifts for this group of workers is useful for ascertaining the extent to which the wage gains we observe among minimum wage workers were driven by changes in macroeconomic conditions or job mobility compared with changes in state minimum wages.

Table 5 presents summary statistics similar to those in table 4, but for individuals whose baseline wage rate was $\$ 5$ to $\$ 7$ higher than their states' minimum wage rates. The table shows that the probability that these supra-minimum-wage workers receive wage increases is similar when comparing individuals in states that did and did not enact minimum wage increases. These findings for supra-minimum-wage workers suggest that the differentials we observe for minimum wage workers may indeed reflect the causal effects of the minimum wage increases per se. That is, this additional evidence supports the view that minimum wage increases were 
responsible for roughly 15 percent of the wage increases experienced by minimum wage workers during years in which states increased their minimum wage rates. The vast majority of wage increases can thus be attributed to other factors, including career progression and the improved state of the economy.

Regression Analysis

To further examine the relationship between wage increases and various factors, we estimate the straightforward regression model below:

$$
y_{i s t}=\beta_{1} m w_{s, t}+\beta_{2} \Delta \ln \left(h p i_{s, t}\right)+\beta_{2} o c c_{i, s, t}+\beta_{3} \text { ind }_{i, s, t}+\beta_{4} \text { union }_{i, s, t}+\alpha_{s}+\tau_{t}+\varepsilon_{i, s, t}
$$

Here $y_{i, s, t}$ is an indicator for whether individual $i$ received a wage gain between their first and second appearance in an outgoing rotation group. Individual $i$ 's state of residence during the baseline interview is indexed by $s$, while the time period of their initial interview is indexed by $t$. The variable $m w_{s, t}$ is an indicator for whether the minimum wage in state $s$ increased during the period between interviews. The variable $\Delta \ln \left(h p i_{s, t}\right)$ is the 3-year change in the house price index, the variable $\operatorname{occ}_{i, s, t}$ indicates whether an individual changed 2-digit occupations between rotations, ind $_{i, s, t}$ indicates whether an individual changed 2-digit industries between rotations, and union $_{i, s, t}$ indicates whether an individual was a union member or covered by a union in their first interview. Finally, $\alpha_{s}$ are state fixed effects and $\tau_{t}$ are time fixed effects. Standard errors are clustered at the state level. 
We present estimates of equation (1) in table 6. The samples in columns 1 and 2 consist of individuals whose baseline wage rates were within $\$ 0.50$ of the minimum wage, while the samples in columns 3 and 4 consist of individuals whose baseline wage rates were between $\$ 5$ and $\$ 7$ greater than the minimum wage. Columns 1 and 3 include all individuals in these baseline wage bands, while columns 2 and 4 restrict the sample to those also employed at the time of their second appearance in an outgoing rotation group.

Consistent with our earlier analysis, we find that minimum wage workers are relatively likely to receive wage increases when the minimum wage rises, when economic conditions improve, when they transition into new occupations or new industries, and when they are members of a union. Put differently, the bivariate correlations presented in table 3 translate into positive partial correlations within equation (1)'s multivariate regression framework. With respect to the minimum wage, the magnitude of the relationship with wage increases is similar to the relationship observed in table 4's summary statistics. Specifically, we find that minimum wage workers were 13.8 percentage points (or just over 21 percent on a base of 65.8 percent) more likely to receive a wage increase if the minimum wage rose between their appearances in outgoing rotation groups. This is modestly larger than estimates based on unadjusted differences between minimum wage workers in states that enacted minimum wage increases relative to those in states that did not. A causal interpretation of this finding is supported in part by the fact we find no significant relationship between minimum wage increases and wage gains in the samples that consist of workers with baseline wage rates that exceeded the minimum wage by $\$ 5$ to $\$ 7$ dollars. The remaining coefficients in table 6 reveal that union membership, occupation changes, industry changes, and housing recoveries predict wage gains for minimum wage workers. Both occupation and industry switches predict wage gains conditional upon one another. For low- 
wage workers, these changes thus appear to be indicative of upward career progression.

Interestingly, these positive correlations are reversed for higher-wage workers, suggesting that for those in higher-wage jobs, job loss and not career progression may drive industry and occupation transitions. Union membership and housing recoveries, by contrast, strongly predict wage gains for both minimum wage workers and workers with higher baseline wages.

\section{Robustness Analysis}

Finally, we examine the sensitivity of our findings along two key dimensions: We explore whether our results are robust to including individuals who lose employment and to tightening the earnings interval defining a minimum wage worker.

Tables A1, A2, and A3 probe the robustness of results presented in tables 2-4 to expanding the sample to include people not employed at the time of their second ORG interview. The results are broadly similar. Minimum wage increases are strongly correlated with wage gains. Wage increases are even more strongly correlated with improvements in the broader economy and job mobility. Workers living in states with minimum wage increases are more likely to see wage gains, but macroeconomic improvements and increased worker mobility across occupations and industries also play a significant role.

In the remaining appendix tables, we explore whether our results are robust to changes in the definition of a minimum wage worker. Tables A4-A6 display information similar to that presented in tables $2-4$, but for a sample restricted to individuals earning within $\$ 0.25$ of the effective minimum wage. For tables A7-A9, we further tighten the restriction to include only 
those earning within $\$ 0.05$ of the effective minimum wage. The key patterns we observe are broadly consistent across each of these samples.

\section{Section IV: Discussion and Conclusion}

In policy discussions, minimum wages can appear to play an outsize role as a driver of low-wage workers' wage increases. Take, as one illustrative example, a July 2021 policy brief from the National Employment Law Project (NELP) titled, "Quantifying the Impact of the Fight for \$15” (Lathrop, Lester, and Wilson, 2021). The report presents estimates "that 26 million workers have been boosted by higher minimum wage policies passed by all levels of government since 2012." It also presents "economic context" that the U.S. has experienced significant productivity growth over the past century, and that "CEO pay has soared" while "worker pay has barely budged" (Lathrop, Lester, and Wilson, 2021). The report's intended message is clear: without a large boost in the wage floor, workers will see scant pay increases. A January 2021 fact sheet from the Economic Policy Institute claims similarly that implementing a $\$ 15$ federal minimum wage would raise wages for 32 million workers (EPI, 2021).

The conclusions of NELP and EPI are based on analyses that require two strong assumptions. First, these analyses depart from the Congressional Budget Office (2019) and broad-based readings of the minimum wage literature (Neumark and Shirley, 2021) by assuming that minimum wage increases have no effect on employment. Second, the analyses assume scant wage gains in the absence of minimum wage increases. ${ }^{6}$

\footnotetext{
${ }^{6}$ The methodology of the NELP (2021) report is built on this assumption. NELP starts with the actual wage distribution in 2011 and then creates a counterfactual wage projection by allowing 2011 wages to grow with
} 
We present these as two examples among many policy-oriented analyses that argue for an outsize role for the importance of minimum wage increases as a source of wage growth among lower-wage workers. These particular reports are among the latest from EPI and NELP, whose analyses have been featured prominently in the public debate. ${ }^{7}$

Our findings reveal that it is easy to overstate the minimum wage's relevance as a source of low-wage workers' wage gains. ${ }^{8}$ We find that state minimum wage changes account for a modest fraction of the wage gains realized by minimum wage workers. Improvements in macroeconomic conditions and progression across occupations and industries appear to play a more significant role.

We find that wage increases are the norm among minimum-wage workers, even in the absence of minimum wage increases. Around seven in 10 minimum-wage workers in states that did not increase their minimum wage at any point in the 2013-2018 period got a raise in any given year, compared to around eight in 10 minimum-wage workers in states that did increase their minimum wage. In a linear probability model, we find that minimum wage increases are associated with a 13.8 percentage point increase in the likelihood that a minimum-wage workers gets a raise.

consumer prices through 2021. NELP classifies workers with projected wages below their state or locality's mandated minimum wage as workers whose wages were affected by increases in minimum wages.

${ }^{7}$ For example, Google search results show that NELP has been cited 64 times by The New York Times and 21 times by The Washington Post in the past year. EPI has been cited 58 times by The New York Times and 79 times by The Washington Post over the same period.

${ }^{8}$ Our analysis focuses on a sample of workers employed at baseline in order to study the relative role of the minimum wage in driving wage increases. This is conceptually distinct from the minimum wage's role in shaping the wage received by new labor market entrants. The NELP and EPI analysis attempts to quantify the impact of a $\$ 15$ per hour minimum wage on both new entrants and continuing workers. 
For those who are persistently employed, our results suggest that both market forces and institutional factors drive short-run wage trajectories for workers at the lower end of the wage distribution. The influence of these factors on longer-term earnings trajectories is an important area for future research. 


\section{References}

Card, David. 2022. "Who Sets Your Wage?” Presidential Address to the American Economic Association.

Carrington, William J., and Bruce C. Fallick. 2001. "Do Some Workers Have Minimum Wage Careers." Monthly Labor Review 124 (May): 17.

Clemens, Jeffrey P., Duncan Hobbs, and Michael Strain. 2018. "A Database on the Passage and Enactment of Recent State Minimum Wage Increases."

Clemens, Jeffrey, and Michael R. Strain. 2017. "Estimating the Employment Effects of Recent Minimum Wage Changes: Early Evidence, an Interpretative Framework, and a PreCommitment to Future Analysis." National Bureau of Economic Research. Working Paper 23084.

Clemens, Jeffrey, and Michael R. Strain. 2018. "The Short-Run Employment Effects of Recent Minimum Wage Changes: Evidence from the American Community Survey." Contemporary Economic Policy 36, no. 4 (October): 711-722.

Clemens, Jeffrey, and Michael R. Strain. 2020. "Understanding "Wage Theft": Evasion and Avoidance Responses to Minimum Wage Increases.” National Bureau of Economic Research. Working Paper 26969.

Clemens, Jeffrey, and Michael R. Strain. 2021. "The Heterogeneous Effects of Large and Small Minimum Wage Changes: Evidence over the Short and Medium Run Using a PreAnalysis Plan.” No. w 29264. National Bureau of Economic Research. Working Paper 29264

CBO (Congressional Budget Office). 2019. "The Effects on Employment and Family Income of Increasing the Federal Minimum Wage.” July 8.

EPI (Economic Policy Institute). 2021. “Why the U.S. Needs a \$15 Minimum Wage.” January 26.

Even, William E., and David A. Macpherson. 2003. "The Wage and Employment Dynamics of Minimum Wage Workers." Southern Economic Journal 69, no 3 (January): 676-690.

Even, William E., and David A. Macpherson. 2004. "Wage Growth Among Minimum Wage Workers." Employment Policies Institute, Washington, DC.

Federal Housing Finance Agency "Quarterly All-Transactions State House Price Index" Released February 28, 2020, (accessed June 15, 2020). https://www.fhfa.gov/DataTools/Downloads/Pages/House-Price-Index-Datasets.aspx\#qat

Jovanovic, Boyan. 1979. "Job Matching and the Theory of Turnover." Journal of Political Economy 87, no. 5 (October): 972-990.

Kahn, Lisa B. 2010. "The Long-Term Labor Market Consequences of Graduating from College in a Bad Economy." Labour Economics 17, no. 2 (April): 303-316. 
Liu, Andrew Yizhou. Forthcoming. "The Minimum Wage and Occupational Mobility." International Economic Review.

Liu, Andrew Yizhou. 2022. "The Short- and Medium-Run Effects of Small and Large Minimum Wage Increases on Occupational Mobility." Unpublished Working Paper.

Long, James E. 1999. "Updated Estimates of the Wage Mobility of Minimum Wage Workers." Journal of Labor Research 20, no. 4 (Fall): 493-503.

Lathrop, Yannet, T. William Lester, and Matthew Wilson. 2021. "Quantifying the Impact of the Fight for \$15: \$150 Billion in Raises for 26 Million Workers, With \$76 Billion Going to Workers of Color." National Employment Law Project. Report.

Neumark, David, and Peter Shirley. 2021. "Myth or Measurement: What Does the New Minimum Wage Research Say About Minimum Wages and Job Loss in the United States?" National Bureau of Economic Research. Working Paper 28388.

Oreopoulos, Philip, Till Von Wachter, and Andrew Heisz. 2012. "The Short-and Long-Term Career Effects of Graduating in a Recession." American Economic Journal: Applied Economics 4, no. 1 (January): 1-29.

Sarah Flood, Miriam King, Renae Rodgers, Steven Ruggles and J. Robert Warren. Integrated Public Use Microdata Series, Current Population Survey: Version 7.0 [dataset]. Minneapolis, MN: IPUMS, 2020. https://doi.org/10.18128/D030.V7.0

Smith, Ralph E., and Bruce Vavrichek. 1992. "The Wage Mobility of Minimum Wage Workers." Industrial and Labor Relations Review 46, no. 1 (October): 82-88.

Stansbury, Anna M., and Lawrence H. Summers. 2017. Productivity and Pay: Is the Link Broken? National Bureau of Economic Research. Working Paper 24165.

Strain, Michael R. 2019. "The Link Between Wages and Productivity Is Strong." The Aspen Institute. February 4.

Topel, Robert H., and Michael P. Ward. 1992. "Job Mobility and the Careers of Young Men." Quarterly Journal of Economics 107, no. 2 (May): 439-479.

U.S. Bureau of Economic Analysis. "Quarterly State Personal Income: Personal Income, Population, and Per Capita Personal Income (SQINC1)" Released March 29, 2020, (accessed June 15, 2020). https://apps.bea.gov/iTable/iTable.cfm

Vaghul, Kavya, and Ben Zipperer. 2016. "Historical State and Sub-State Minimum Wage Data." Washington Center for Equitable Growth. Dataset updated 2021. 
Tables and Figures

Table 1: List of States With and Without Minimum Wage Changes from 2010-2019

\begin{tabular}{ll}
\hline No Minimum Wage Changes & Minimum Wage Changes \\
Alabama & Alaska \\
Georgia & Arizona \\
Idaho & Arkansas \\
Indiana & California \\
Iowa & Colorado \\
Kansas & Connecticut \\
Kentucky & Delaware \\
Louisiana & District of Columbia \\
Mississippi & Florida \\
New Hampshire & Hawaii \\
New Mexico & Illinois \\
North Carolina & Maine \\
North Dakota & Maryland \\
Oklahoma & Massachusetts \\
Pennsylvania & Michigan \\
South Carolina & Minnesota \\
Tennessee & Missouri \\
Texas & Montana \\
Utah & Nebraska \\
Virginia & Nevada \\
Wisconsin & New Jersey \\
Wyoming & New York \\
& Ohio \\
& Oregon \\
& Rhode Island \\
& South Dakota \\
& Vermont \\
& Washington \\
\hline \hline Nost Virginia \\
\hline
\end{tabular}

Notes: Data on minimum wage changes comes from the U.S. Department of Labor. States are counted as no change states if the minimum wage rate in force in that state did not change between January 1, 2010 and December 31, 2019. States are counted as having minimum wage changes if the state effective minimum wage rate on December 31, 2019 was higher than on January 1, 2010. 
Table 2: Summary Statistics for Individuals Earning Within $\mathbf{\$ 0 . 5 0}$ of the Minimum Wage in Their First Rotation, Employed in Both Rotations

Sample

Year of first outgoing rotation

Variable

Increased wage from first outgoing rotation

Decreased wage from first outgoing rotation

Same wage as first outgoing rotation

Share of months in sample employed

1 -year change in hourly wage $(\$)$

Size of hourly wage increase $(\$)$

1 -year change in effective minimum wage (\$)

1-year change in FHFA house price index

1 -year change in state per capita income (\$)

1 -year change in state mid-skill employment

1 -year change in state prime-age employment

Education increase

Covered by union in first outgoing rotation

3 -year change in FHFA house price index

3 -year change in state per capita income (\$)

3 -year change in state mid-skill employment

3 -year change in state prime-age employment

Changed 1-digit occupation

Changed 1-digit industry

Changed 2-digit occupation

Changed 2-digit industry

Changed 3-digit occupation

Changed 3-digit industry

Observations
(1) (2)

Workers Living in States

that Never Increased

(3)

(4)

Workers Living in States that

Increased the Minimum Wage

Minimum Wage, 2010-2019 at Least Once, 2010-2019

2010-2012 2013-2018

2010-2012 2013-2018 2010-2012 2013-2018

\begin{tabular}{|c|c|c|c|}
\hline 0.658 & 0.711 & 0.678 & 0.788 \\
\hline 0.125 & 0.106 & 0.126 & 0.0812 \\
\hline 0.217 & 0.183 & 0.197 & 0.131 \\
\hline 0.919 & 0.919 & 0.930 & 0.930 \\
\hline 1.014 & 1.381 & 1.135 & 1.661 \\
\hline 1.749 & 2.125 & 1.802 & 2.223 \\
\hline 0 & 0 & 0.0574 & 0.410 \\
\hline-0.745 & 14.34 & 0.348 & 27.33 \\
\hline 1613.0 & 1480.9 & 1457.5 & 2225.2 \\
\hline 0.00244 & 0.00717 & 0.00326 & 0.0102 \\
\hline 0.00272 & 0.00480 & 0.00361 & 0.00782 \\
\hline 0.308 & 0.368 & 0.264 & 0.267 \\
\hline 0.0177 & 0.0172 & 0.0402 & 0.0531 \\
\hline-13.37 & 34.07 & -33.69 & 74.73 \\
\hline 3996.4 & 3884.6 & 3958.7 & 5841.6 \\
\hline-0.0176 & 0.0150 & -0.0297 & 0.0352 \\
\hline-0.0157 & 0.0108 & -0.0222 & 0.0220 \\
\hline 0.350 & 0.371 & 0.319 & 0.361 \\
\hline 0.231 & 0.252 & 0.223 & 0.254 \\
\hline 0.485 & 0.487 & 0.441 & 0.471 \\
\hline 0.354 & 0.373 & 0.331 & 0.375 \\
\hline 0.539 & 0.567 & 0.505 & 0.525 \\
\hline 0.361 & 0.382 & 0.346 & 0.388 \\
\hline 1,412 & 1,398 & 2,391 & 4,234 \\
\hline
\end{tabular}

Notes: This table reports summary statistics for two sample groups ages 16-64 regarding the changes in key labor market indicators between rounds 4 and 8 of the CPS. Columns 1 and 2 display variable means for individuals living in states with no minimum wage increases between 2010 and 2019 and columns 3 and 4 display means for individuals living in states with at least one increase in the minimum wage between 2010 and 2019. Columns 1 and 3 include all individuals who were in their first outgoing rotation in 2010-2012 and columns 2 and 4 include all individuals who were in their first outgoing rotation from 20132018. T The sample is from the CPS Outgoing Rotation Groups and consists of individuals who were employed, reported positive wages, were paid by the hour, did not have imputed wage rates in both of their outgoing rotations, and who earned within $\$ 0.50$ of the effective minimum wage in their first rotation. 


\section{Table 3: Correlations Between Changes in Reported Hourly Wages and Macroeconomic Indicators for Individuals Employed in Both Rotations and Earning Within \$0.50 of the Minimum Wage in Their First Rotation}

\section{Variable}

State ever had minimum wage change from 2010-2019

State had minimum wage increase between rotations

$0.0705 * * *$

First rotation in 2013-2018

$0.0713 * * *$

Share of months in sample employed

$-0.00725$

1 -year change in effective minimum wage (\$)

$0.0773 * * *$

1-year change in FHFA house price index

$0.0780 * * *$

1-year change in state per capita income

$0.0358 * * *$

1-year change in state mid-skill employment

$0.0230 *$

1 -year change in state prime-age employment

Education increase between rotations

Covered by union in first outgoing rotation

3 -year change in FHFA house price index

3 -year change in state per capita income (\$)

3 -year change in state mid-skill employment

3 -year change in state prime-age employment

Changed 1-digit occupation

$0.109 * * *$

Changed 1-digit industry

$0.122 * * *$

Changed 2-digit occupation

$0.0970 * * *$

Changed 2-digit industry

$0.125 * * *$

Changed 3-digit occupation

Changed 3-digit industry

$0.128 * * *$

Observations

9,435

This table displays bivariate correlations between the change in reported hourly wages between outgoing rotations for individuals ages 16-64 in the Current Population Survey and changes in other key macroeconomic and individual indicators. The sample is from the CPS Outgoing Rotation Groups and consists of individuals who were employed, reported positive wages, were paid by the hour, did not have imputed wage rates in both of their outgoing rotations, and earned within $\$ 0.50$ of the effective minimum wage in their first rotation. $* * * \mathrm{p}<0.01, * *$ $\mathrm{p}<0.05, * \mathrm{p}<0.1$ 


\section{Table 4: Summary Statistics for Individuals Earning Within $\$ 0.50$ of the Minimum Wage in Their First Rotation, Employed in Both Rotations}

\begin{tabular}{|c|c|c|c|c|}
\hline \multirow{2}{*}{$\begin{array}{l}\text { Sample } \\
\text { Year of first outgoing rotation }\end{array}$} & \multicolumn{2}{|c|}{$\begin{array}{c}(1) \\
\text { No Minimum Wage Increase } \\
\text { Between CPS ORG Rotations }\end{array}$} & \multicolumn{2}{|c|}{$\begin{array}{c}(3) \\
\text { Minimum Wage Increase } \\
\text { Between CPS ORG Rotations }\end{array}$} \\
\hline & 2010-2012 & 2013-2018 & 2010-2012 & 2013-2018 \\
\hline \multicolumn{5}{|l|}{$\underline{\text { Variable }}$} \\
\hline Increased wage from first outgoing rotation & 0.649 & 0.695 & 0.764 & 0.826 \\
\hline Decreased wage from first outgoing rotation & 0.125 & 0.111 & 0.127 & 0.0688 \\
\hline Same wage as first outgoing rotation & 0.226 & 0.194 & 0.109 & 0.105 \\
\hline Share of months in sample employed & 0.925 & 0.922 & 0.929 & 0.932 \\
\hline 1-year change in hourly wage $(\$)$ & 1.075 & 1.324 & 1.153 & 1.797 \\
\hline Size of hourly wage increase $(\$)$ & 1.820 & 2.082 & 1.645 & 2.278 \\
\hline 1-year change in effective minimum wage $(\$)$ & 0 & 0 & 0.193 & 0.546 \\
\hline 1-year change in FHFA house price index & 0.136 & 18.20 & -0.902 & 28.65 \\
\hline 1-year change in state per capita income $(\$)$ & 1556.7 & 1681.6 & 1334.3 & 2317.0 \\
\hline 1-year change in state mid-skill employment & 0.00259 & 0.00859 & 0.00457 & 0.0101 \\
\hline 1-year change in state prime-age employment & 0.00345 & 0.00596 & 0.00254 & 0.00792 \\
\hline Education increase & 0.291 & 0.335 & 0.236 & 0.260 \\
\hline Covered by union in first outgoing rotation & 0.0314 & 0.0306 & 0.0339 & 0.0547 \\
\hline 3-year change in FHFA house price index & -23.97 & 43.26 & -35.63 & 81.12 \\
\hline 3-year change in state per capita income $(\$)$ & 4103.3 & 4307.5 & 3402.5 & 6163.6 \\
\hline 3-year change in state mid-skill employment & -0.0238 & 0.0201 & -0.0316 & 0.0379 \\
\hline 3-year change in state prime-age employment & -0.0191 & 0.0113 & -0.0228 & 0.0252 \\
\hline Changed 1-digit occupation & 0.338 & 0.360 & 0.299 & 0.366 \\
\hline Changed 1-digit industry & 0.226 & 0.242 & 0.228 & 0.262 \\
\hline Changed 2-digit occupation & 0.460 & 0.473 & 0.444 & 0.476 \\
\hline Changed 2-digit industry & 0.343 & 0.366 & 0.327 & 0.381 \\
\hline Changed 3-digit occupation & 0.519 & 0.539 & 0.511 & 0.532 \\
\hline Changed 3-digit industry & 0.354 & 0.375 & 0.343 & 0.395 \\
\hline Observations & 3,094 & 2,451 & 709 & 3,181 \\
\hline
\end{tabular}

Notes: This table reports summary statistics for two sample groups ages 16-64 regarding the changes in key labor market indicators between rounds 4 and 8 of the CPS. Columns 1 and 2 display variable means for individuals living in states with no minimum wage increases between outgoing rotations and columns 3 and 4 display means for individuals living in states with at least one increase in the minimum wage between outgoing rotations. Columns 1 and 3 include all individuals who were in their first outgoing rotation in 2010-2012 and columns 2 and 4 include all individuals who were in their first outgoing rotation in 2013-2018. The sample is from the CPS Outgoing Rotation Groups and consists of individuals who were employed, reported positive wages, were paid by the hour, did not have imputed wage rates in both of their outgoing rotations, and earned within $\$ 0.50$ of the effective minimum wage in their first rotation. 


\section{Table 5: Summary Statistics for Individuals Earning \$5 to \$7 More than the Minimum Wage in}

Their First Rotation, Employed in Both Rotations

\begin{tabular}{|c|c|c|c|c|}
\hline \multirow{2}{*}{$\begin{array}{l}\text { Sample } \\
\text { Year of first outgoing rotation }\end{array}$} & \multicolumn{2}{|c|}{$\begin{array}{c}(1) \quad(2) \\
\text { Workers Living in States } \\
\text { that Never Increased } \\
\text { Minimum Wage, 2010- } \\
2019\end{array}$} & \multicolumn{2}{|c|}{$\begin{array}{l}(3) \\
\text { Workers Living in States } \\
\text { that Increased the } \\
\text { Minimum Wage at Least } \\
\text { Once, 2010-2019 }\end{array}$} \\
\hline & 2010-2012 & $2013-2018$ & 2010-2012 & 2013-2018 \\
\hline \multicolumn{5}{|l|}{$\underline{\text { Variable }}$} \\
\hline Increased wage from first outgoing rotation & 0.588 & 0.628 & 0.570 & 0.598 \\
\hline Decreased wage from first outgoing rotation & 0.244 & 0.226 & 0.262 & 0.238 \\
\hline Same wage as first outgoing rotation & 0.169 & 0.146 & 0.167 & 0.165 \\
\hline Share of months in sample employed & 0.982 & 0.980 & 0.980 & 0.979 \\
\hline 1-year change in hourly wage $(\$)$ & 0.793 & 1.070 & 0.893 & 1.152 \\
\hline Size of hourly wage increase conditional on increase $(\$)$ & 2.162 & 2.365 & 2.497 & 2.843 \\
\hline 1-year change in effective minimum wage $(\$)$ & 0 & 0 & 0.0580 & 0.389 \\
\hline 1-year change in FHFA house price index & 0.0322 & 16.01 & 0.00489 & 23.84 \\
\hline 1-year change in state per capita income $(\$)$ & 1528.4 & 1552.2 & 1477.0 & 2041.7 \\
\hline 1-year change in state mid-skill employment & -0.000589 & 0.00732 & 0.00371 & 0.00886 \\
\hline 1-year change in state prime-age employment & 0.00205 & 0.00498 & 0.00286 & 0.00673 \\
\hline Education increase & 0.100 & 0.115 & 0.101 & 0.105 \\
\hline Covered by union in first outgoing rotation & 0.102 & 0.0595 & 0.154 & 0.127 \\
\hline 3-year change in FHFA house price index & -12.88 & 40.08 & -29.24 & 64.09 \\
\hline 3-year change in state per capita income $(\$)$ & 4298.7 & 4021.5 & 4117.6 & 5369.3 \\
\hline 3-year change in state mid-skill employment & -0.0227 & 0.0268 & -0.0288 & 0.0333 \\
\hline 3-year change in state prime-age employment & -0.0143 & 0.0157 & -0.0177 & 0.0201 \\
\hline Changed 1-digit occupation & 0.290 & 0.313 & 0.281 & 0.307 \\
\hline Changed 1-digit industry & 0.198 & 0.220 & 0.200 & 0.218 \\
\hline Changed 2-digit occupation & 0.424 & 0.440 & 0.425 & 0.431 \\
\hline Changed 2-digit industry & 0.290 & 0.333 & 0.309 & 0.328 \\
\hline Changed 3-digit occupation & 0.466 & 0.483 & 0.465 & 0.472 \\
\hline Changed 3-digit industry & 0.311 & 0.353 & 0.326 & 0.344 \\
\hline Observations & 2,135 & 3,678 & 3,195 & 5,258 \\
\hline
\end{tabular}

Notes: This table reports summary statistics for two sample groups ages 16-64 regarding the changes in key labor market indicators between rounds 4 and 8 of the CPS. Columns 1 and 2 display variable means for individuals living in states with no minimum wage increases between 2010 and 2019 and columns 3 and 4 display means for individuals living in states with at least one increase in the minimum wage between 2010 and 2019. Columns 1 and 3 include all individuals who were in their first outgoing rotation in 2010-2012 and columns 2 and 4 include all individuals who were in their first outgoing rotation in 2013-2018. The sample is from the CPS Outgoing Rotation Groups and consists of individuals who were employed and reported positive wages, were paid by the hour, and did not have imputed wage rates in both of their outgoing rotations, and earned between 5 and 7 dollars more per hour than the effective minimum wage in their first rotation. 


\section{Table 6: Relationship Between Minimum Wage Increases and Probability of Earnings Increases Between Rotations}

(1)

(3)

(4)

Dependent Variable: Earned higher wages in second rotation

\begin{tabular}{|c|c|c|c|c|}
\hline & \multicolumn{2}{|c|}{$\begin{array}{l}\text { Workers earning within } \$ 0.50 \text { of the } \\
\text { min wage }\end{array}$} & \multicolumn{2}{|c|}{$\begin{array}{c}\text { Workers earning } \$ 5-\$ 7 \text { more than min } \\
\text { wage }\end{array}$} \\
\hline & $\begin{array}{l}\text { Workers } \\
\text { employed in the } \\
\text { first outgoing } \\
\text { rotation }\end{array}$ & $\begin{array}{l}\text { Workers } \\
\text { employed in } \\
\text { both outgoing } \\
\text { rotations }\end{array}$ & $\begin{array}{l}\text { Workers } \\
\text { employed in the } \\
\text { first outgoing } \\
\text { rotation }\end{array}$ & $\begin{array}{l}\text { Workers } \\
\text { employed in } \\
\text { both outgoing } \\
\text { rotations }\end{array}$ \\
\hline $\begin{array}{l}\text { State increased minimum wage } \\
\text { between rotations }\end{array}$ & $\begin{array}{c}0.125 * * * \\
(0.019)\end{array}$ & $\begin{array}{c}0.138 * * * \\
(0.020)\end{array}$ & $\begin{array}{c}0.003 \\
(0.013)\end{array}$ & $\begin{array}{l}-0.002 \\
(0.017)\end{array}$ \\
\hline 3-year change in log HPI & $\begin{array}{l}0.167 * \\
(0.086)\end{array}$ & $\begin{array}{l}0.193^{*} \\
(0.098)\end{array}$ & $\begin{array}{c}0.144 * * * \\
(0.046)\end{array}$ & $\begin{array}{l}0.121 * * \\
(0.046)\end{array}$ \\
\hline $\begin{array}{l}\text { Changed 2-digit occupation } \\
\text { between rotations }\end{array}$ & $\begin{array}{c}0.034 * * * \\
(0.008)\end{array}$ & $\begin{array}{c}0.064 * * * \\
(0.009)\end{array}$ & $\begin{array}{l}-0.009 \\
(0.007)\end{array}$ & $\begin{array}{l}-0.013^{*} \\
(0.007)\end{array}$ \\
\hline $\begin{array}{l}\text { Changed 2-digit industry } \\
\text { between rotations }\end{array}$ & $\begin{array}{c}0.016 \\
(0.011)\end{array}$ & $\begin{array}{l}0.071 * * * \\
(0.009)\end{array}$ & $\begin{array}{c}-0.040 * * * \\
(0.009)\end{array}$ & $\begin{array}{c}-0.039 * * * \\
(0.010)\end{array}$ \\
\hline $\begin{array}{l}\text { Covered by union in first } \\
\text { rotation }\end{array}$ & $\begin{array}{c}0.104 * * * \\
(0.022)\end{array}$ & $\begin{array}{c}0.088 * * * \\
(0.022)\end{array}$ & $\begin{array}{c}0.064 * * * \\
(0.013)\end{array}$ & $\begin{array}{c}0.077 * * * \\
(0.014)\end{array}$ \\
\hline Adjusted R-squared & 0.025 & 0.049 & 0.009 & 0.012 \\
\hline Observations & 11,184 & 9,435 & 18718 & 14,266 \\
\hline
\end{tabular}

Notes: This table displays regression results examining whether workers are likely to report earning higher wages in states passing minimum wage increases. The sample is CPS ORG respondents who had their first outgoing rotation between 2010 and 2018, were employed and reported positive wages, were paid by the hour, and did not have imputed wage rates. The dependent variable is a dichotomous indicator equal to 1 if a respondent reported earning a higher hourly wage in their second outgoing rotation group compared with their first outgoing rotation group. Column 1 includes respondents who were employed in their first outgoing rotation group and reported earning within $\$ 0.50$ of the effective minimum wage. Column 2 restricts the sample to respondents who were employed and reported positive wages, were paid by the hour, and did not have imputed wage rates in both rotations. Column 3 includes respondents who were employed in their first outgoing rotation group and reported earning $\$ 5$ to $\$ 7$ more than effective minimum wage. Column 4 restricts the sample to respondents who were employed and reported positive wages, were paid by the hour, and did not have imputed wage rates in both rotations. All specifications include state, year, month, and yearmonth fixed effects based on the first rotation. Standard errors clustered by state in first rotation. $* * * \mathrm{p}<0.01$, ** $\mathrm{p}<0.05,{ }^{*} \mathrm{p}<0.1$ 


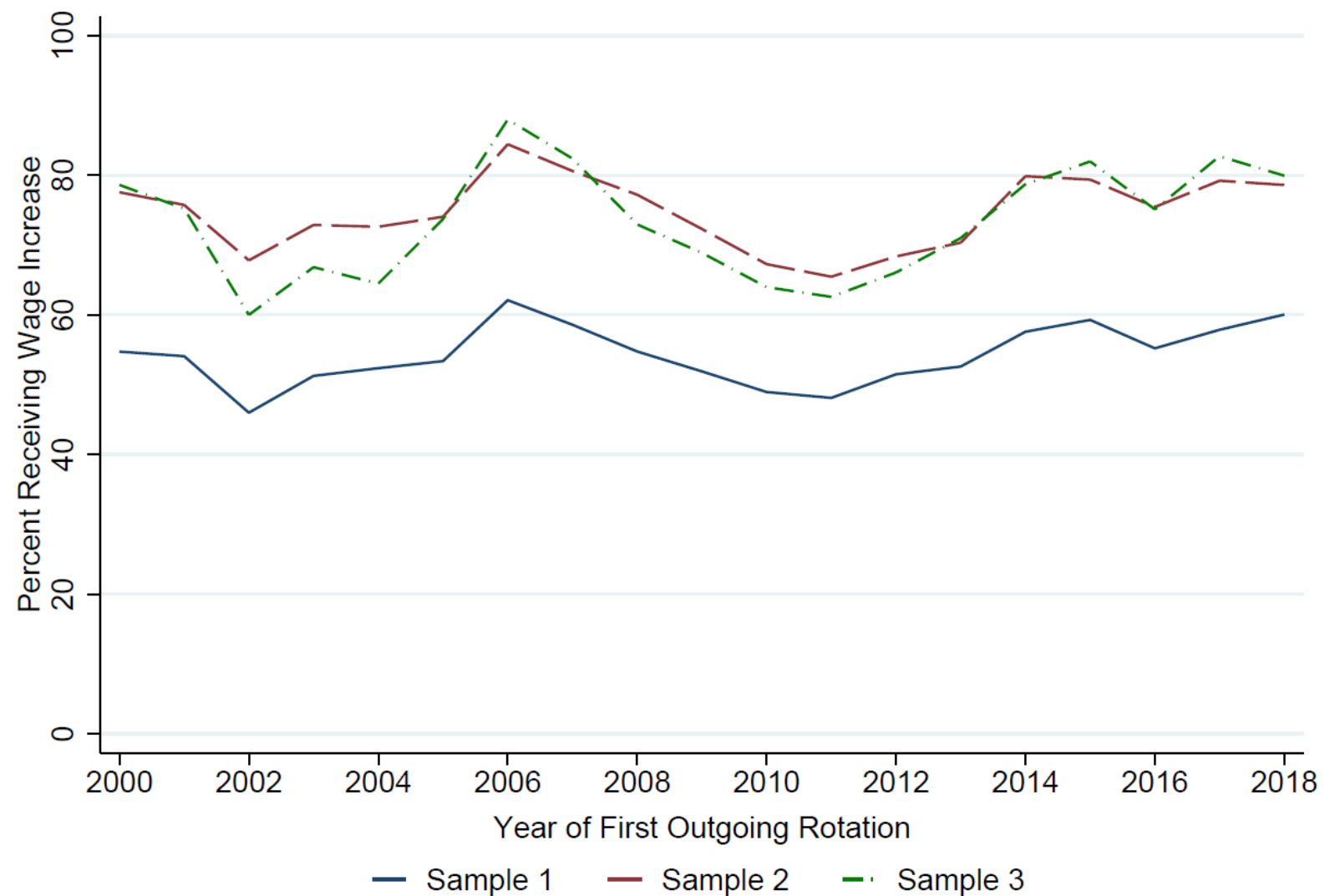

Figure 1: Share of Individuals in CPS ORG Receiving a Wage Increase in Second Rotation. This figure shows the share of respondents in the CPS Outgoing Rotation Groups who reported earning a higher hourly wage in their second outgoing rotation compared with their first outgoing rotation. All samples include people who were paid by the hour and did not have imputed wage rates. Sample 1 includes people employed and earning within $\$ 0.50$ of the effective minimum wage in their first outgoing rotation. Sample 2 includes people employed in both outgoing rotations and earning within $\$ 0.50$ of the effective minimum wage in their first outgoing rotation. Sample 3 includes people employed in both outgoing rotations and earning within $\$ 0.05$ of the effective minimum wage in their first outgoing rotation. 
Appendix Tables 


\section{Table A1: Summary Statistics for Individuals Earning Within $\mathbf{\$ 0 . 5 0}$ of the Minimum Wage in Their First Rotation, Employed in First Rotation}

(1)

Workers Living in States that

Sample

Year of first outgoing rotation

Variable

Became unemployed in second rotation

Increased wage from first outgoing rotation

Decreased wage from first outgoing rotation

Same wage as first outgoing rotation

Share of months in sample employed

1 -year change in hourly wage if remaining employed (\$)

Size of hourly wage increase conditional on increase (\$)

1-year change in effective minimum wage (\$)

1-year change in FHFA house price index

1 -year change in state per capita income (\$)

1 -year change in state mid-skill employment

1 -year change in state prime-age employment

Education increase

Covered by union in first outgoing rotation

3 -year change in FHFA house price index

3 -year change in state per capita income (\$)

3-year change in state mid-skill employment

3 -year change in state prime-age employment

Changed 1-digit occupation

Changed 1-digit industry

Changed 2-digit occupation

Changed 2-digit industry

Changed 3-digit occupation

Changed 3-digit industry

Observations

Notes: This table reports summary statistics for two sample groups regarding the changes in key labor market indicators between rounds 4 and 8 of the CPS. Columns 1 and 2 display variable means for individuals living in states with no minimum wage increases between 2010 and 2019 and columns 3 and 4 display means for individuals living in states with an increase in the minimum wage between 2010 and 2019. Columns 1 and 3 include all individuals who were in their first outgoing rotation group from 2010-2012 and columns 2 and 4 include all individuals who were in their first outgoing rotation group from 20132018. The sample is from the CPS Outgoing Rotation Groups and consists of individuals who were employed, reported positive wages, were paid by the hour, did not have imputed wage rates, and earned within $\$ 0.50$ of the state effective minimum wage in their first outgoing rotation and were paid by the hour and had non-imputed wages if they were employed in their second rotation.

(3)

(4)

Workers Living in States that

Increased the Minimum Wage

at Least Once, 2010-2019

2010-2012 2013-2018 2010-2012 2013-2018

\begin{tabular}{cccc}
0.284 & 0.292 & 0.248 & 0.249 \\
0.471 & 0.503 & 0.509 & 0.592 \\
0.0897 & 0.0749 & 0.0947 & 0.0610 \\
0.155 & 0.130 & 0.148 & 0.0980 \\
0.829 & 0.825 & 0.844 & 0.850 \\
1.014 & 1.381 & 1.135 & 1.661 \\
1.749 & 2.125 & 1.802 & 2.223 \\
0 & 0 & 0.0565 & 0.407 \\
-0.941 & 14.38 & 0.187 & 27.05 \\
1592.8 & 1457.5 & 1467.4 & 2224.0 \\
0.00120 & 0.00682 & 0.00359 & 0.00978 \\
0.00259 & 0.00489 & 0.00345 & 0.00756 \\
0.349 & 0.390 & 0.293 & 0.290 \\
0.0141 & 0.0178 & 0.0376 & 0.0423 \\
-13.89 & 34.23 & -33.40 & 73.85 \\
3943.4 & 3815.5 & 3958.5 & 5810.1 \\
-0.0184 & 0.0150 & -0.0300 & 0.0345 \\
-0.0151 & 0.0104 & -0.0217 & 0.0216 \\
0.366 & 0.387 & 0.335 & 0.370 \\
0.249 & 0.269 & 0.245 & 0.270 \\
0.503 & 0.508 & 0.459 & 0.482 \\
0.378 & 0.394 & 0.356 & 0.389 \\
0.561 & 0.582 & 0.521 & 0.534 \\
0.385 & 0.402 & 0.370 & 0.402 \\
1,973 & 1,975 & 3,180 & 5,641 \\
\hline
\end{tabular}




\section{Table A2: Correlations Between Changes in Reported Hourly Wages and Macroeconomic Indicators for Individuals Employed in Their First Rotation and Earning Within \$0.50 of the Minimum Wage in Their First Rotation}

\begin{tabular}{lc}
\hline Variable & \\
State ever had minimum wage change from 2010-2019 & $0.0364^{* * *}$ \\
State had minimum wage increase between rotations & $0.0705^{* * *}$ \\
First Rotation in 2013-2018 & $0.0713^{* * *}$ \\
Share of months in sample employed & -0.00725 \\
1-year change in effective minimum wage $(\$)$ & $0.0773^{* * *}$ \\
1-year change in FHFA house price index & $0.0780^{* * *}$ \\
1-year change in state per capita income & $0.0358^{* * *}$ \\
1-year change in state mid-skill employment & $0.0230^{*}$ \\
1-year change in state prime-age employment & -0.0172 \\
Education increase & -0.0167 \\
Covered by union in first outgoing rotation & $0.0434^{* * *}$ \\
3-year change in FHFA house price index & $0.0857^{* * *}$ \\
3-year change in state per capita income (\$) & $0.0618^{* * *}$ \\
3-year change in state mid-skill employment & $0.0566^{* * *}$ \\
3-year change in state prime-age employment & $0.0494^{* * *}$ \\
Changed 1-digit occupation & $0.109^{* * *}$ \\
Changed 1-digit industry & $0.122^{* * *}$ \\
Changed 2-digit occupation & $0.0970^{* * *}$ \\
Changed 2-digit industry & $0.125^{* * *}$ \\
Changed 3-digit occupation & $0.0812^{* * *}$ \\
Changed 3-digit industry & $0.128^{* * *}$ \\
\hline Observations & 12,769 \\
\hline \hline This & \\
\hline
\end{tabular}

This table displays bivariate correlations between the change in reported hourly wages between outgoing rotations for individuals in the Current Population Survey and changes in other key macroeconomic and individual indicators. The sample is from the CPS Outgoing Rotation Groups and consists of individuals who were employed, reported positive wages, were paid by the hour, did not have imputed wage rates, and earned within $\$ 0.50$ of the state effective minimum wage in their first outgoing rotation, and were paid by the hour and had nonimputed wages if they were employed in their second rotation. $* * * \mathrm{p}<0.01, * * \mathrm{p}<0.05, * \mathrm{p}<0.1$ 


\section{Table A3: Summary Statistics for Individuals Earning within $\mathbf{\$ 0 . 5}$ of the Minimum Wage in Their First Rotation, Employed in First Rotation}

(1)

No Minimum Wage Increase

Sample

Year of first outgoing rotation

Variable

Became unemployed in second rotation

Increased wage from first outgoing rotation

Decreased wage from first outgoing rotation

Same wage as first outgoing rotation

Share of months in sample employed

1 -year change in hourly wage if remaining employed (\$)

Size of hourly wage increase conditional on increase (\$)

1 -year change in effective minimum wage (\$)

1-year change in FHFA house price index

1-year change in state per capita income (\$)

1 -year change in state mid-skill employment

1 -year change in state prime-age employment

Education increase

Covered by union in first outgoing rotation

3 -year change in FHFA house price index

3 -year change in state per capita income (\$)

3 -year change in state mid-skill employment

3 -year change in state prime-age employment

Changed 1-digit occupation

Changed 1-digit industry

Changed 2-digit occupation

Changed 2-digit industry

Changed 3-digit occupation

Changed 3-digit industry
Between CPS ORG Rotations

2010-2012

0.266

0.476

0.0920

0.166

0.809

1.075

1.820

0

0.00160

1547.7

0.00214

0.00329

0.324

0.0320

$-23.64$

4087.9

$-0.0243$

$-0.0184$

0.352

0.245

0.477

0.365

0.537

0.376

4,217 2013-2018

0.275

0.504

0.140

17.98

1664.5

0.00588
(3)

(4)

Minimum Wage Increase Between CPS ORG Rotations

2010-2012 2013-2018

0.243

0.249

0.579

0.621

0.0962

0.0517

0.0789

0.0823

0.856

0.869

1.797

1.153

2.278

0.542

0.192

28.38

$-1.356$

2313.2

1369.8

0.00984

0.00764

0.00509

0.285

0.270

0.0386

0.0253

80.03

6124.3

0.0371

3343.7

0.0247

0.374

0.324

0.277

0.254

0.487

0.468

0.395

0.542

0.409

Observations

Notes: This table reports summary statistics for two sample groups regarding the changes in key labor market indicators between rounds 4 and 8 of the CPS. Columns 1 and 2 display variable means for individuals living in states with no minimum wage increases between outgoing rotations and columns 3 and 4 display means for individuals living in states with an increase in the minimum wage between outgoing rotations. Columns 1 and 3 include all individuals who were in their first outgoing rotation group from 2010-2012 and columns 2 and 4 include all individuals who were in their first outgoing rotation group from 2013-2018. The sample is from the CPS Outgoing Rotation Groups and consists of individuals who were employed, reported positive wages, were paid by the hour, did not have imputed wage rates, and earned within $\$ 0.50$ of the effective minimum wage in their first outgoing rotation, and were paid by the hour and had non-imputed wages if they were employed in their second rotation. 
Table A4: Summary Statistics for Individuals Earning Within \$0.25 of the Minimum Wage in Their First Rotation, Employed in Both Rotations

\begin{tabular}{|c|c|c|c|c|}
\hline \multirow{2}{*}{$\begin{array}{l}\text { Sample } \\
\text { Year of first outgoing rotation }\end{array}$} & \multicolumn{2}{|c|}{$\begin{array}{l}(1) \\
\text { Workers Living in States that } \\
\text { Never Increased Minimum } \\
\text { Wage, 2010-2019 }\end{array}$} & \multicolumn{2}{|c|}{$\begin{array}{l}\text { (3) } \\
\text { Workers Living in States that } \\
\text { Increased the Minimum Wage } \\
\text { at Least Once, 2010-2019 }\end{array}$} \\
\hline & $2010-2012$ & 2013-2018 & $2010-2012$ & 2013-2018 \\
\hline \multicolumn{5}{|l|}{$\underline{\text { Variable }}$} \\
\hline Increased wage from first outgoing rotation & 0.646 & 0.712 & 0.689 & 0.794 \\
\hline Decreased wage from first outgoing rotation & 0.122 & 0.101 & 0.0979 & 0.0710 \\
\hline Same wage as first outgoing rotation & 0.232 & 0.187 & 0.213 & 0.135 \\
\hline Share of months in sample employed & 0.916 & 0.914 & 0.927 & 0.928 \\
\hline 1 -year change in hourly wage $(\$)$ & 0.979 & 1.418 & 1.078 & 1.620 \\
\hline Size of hourly wage increase $(\$)$ & 1.741 & 2.177 & 1.670 & 2.146 \\
\hline 1-year change in effective minimum wage $(\$)$ & 0 & 0 & 0.0476 & 0.403 \\
\hline 1-year change in FHFA house price index & -0.761 & 14.62 & 0.139 & 27.06 \\
\hline 1 -year change in state per capita income $(\$)$ & 1627.0 & 1494.0 & 1478.7 & 2199.0 \\
\hline 1-year change in state mid-skill employment & 0.00280 & 0.00804 & 0.00297 & 0.0101 \\
\hline 1-year change in state prime-age employment & 0.00284 & 0.00522 & 0.00383 & 0.00780 \\
\hline Education increase & 0.322 & 0.391 & 0.270 & 0.271 \\
\hline Covered by union in first outgoing rotation & 0.0161 & 0.0145 & 0.0355 & 0.0523 \\
\hline 3-year change in FHFA house price index & -13.29 & 34.94 & -33.40 & 74.07 \\
\hline 3-year change in state per capita income $(\$)$ & 3970.5 & 3917.6 & 3965.9 & 5791.8 \\
\hline 3-year change in state mid-skill employment & -0.0173 & 0.0168 & -0.0292 & 0.0335 \\
\hline 3-year change in state prime-age employment & -0.0157 & 0.0111 & -0.0225 & 0.0196 \\
\hline Changed 1-digit occupation & 0.351 & 0.363 & 0.317 & 0.366 \\
\hline Changed 1-digit industry & 0.233 & 0.261 & 0.227 & 0.249 \\
\hline Changed 2-digit occupation & 0.491 & 0.485 & 0.441 & 0.471 \\
\hline Changed 2-digit industry & 0.354 & 0.379 & 0.331 & 0.367 \\
\hline Changed 3-digit occupation & 0.545 & 0.561 & 0.508 & 0.525 \\
\hline Changed 3-digit industry & 0.362 & 0.387 & 0.346 & 0.377 \\
\hline Observations & 1,183 & 1,172 & 1,777 & 3,001 \\
\hline
\end{tabular}

Notes: This table reports summary statistics for two sample groups regarding the changes in key labor market indicators between rounds 4 and 8 of the CPS. Columns 1 and 2 display variable means for individuals living in states with at least one minimum wage increase between 2010 and 2019 and columns 3 and 4 display means for individuals living in states with increases in the minimum wage between 2010 and 2019. Columns 1 and 3 include all individuals who were in their first outgoing rotation group from 2010-2012 and columns 2 and 4 include all individuals who were in their first outgoing rotation group from 2013-2018. The sample is from the CPS Outgoing Rotation Groups and consists of individuals who were employed, reported positive wages, were paid by the hour, and did not have imputed wage rates in both of their outgoing rotations, and who earned within $\$ 0.25$ of the effective minimum wage in their first rotation. 


\section{Table A5: Correlations Between Changes in Reported Hourly Wage and Macroeconomic Indicators for Individuals Employed in Both Rotations and Earning Within \$0.25 of the Minimum Wage in Their First Rotation}

$\underline{\text { Variable }}$

State ever had minimum wage change from 2010-2019

$0.0298 *$

$0.0637 * * *$

State had minimum wage increase between outgoing rotations

First outgoing rotation 2013-2018

$0.0743 * * *$

0.00109

Share of months in sample employed

$0.0759 * * *$

-year change in effective minimum wage (\$)

$0.0741 * * *$

1 -year change in FHFA house price index

$0.0317 * *$

1 -year change in state mid-skill employment

$0.0293^{*}$

1 -year change in state prime-age employment

$-0.0218$

$-0.0251^{*}$

Covered by union in first outgoing rotation

3 -year change in FHFA house price index

$0.0388 * *$

$0.0829 * * *$

3-year change in state per capita income (\$)

$0.0531 * * *$

3 -year change in state mid-skill employment

$0.0606 * * *$

3 -year change in state prime-age employment

$0.0453 * *$

Changed 1-digit occupation

$0.110 * * *$

Changed 1-digit industry

$0.126^{* * * *}$

Changed 2-digit occupation

$0.0932 * * *$

Changed 2-digit industry

$0.127 * * *$

Changed 3-digit occupation

$0.0796 * * *$

Changed 3-digit industry

Observations 7,133

This table displays bivariate correlations between the change in reported hourly wages between outgoing rotations for individuals in the Current Population Survey and changes in other key macroeconomic and individual indicators. The sample is from the CPS Outgoing Rotation Groups and consists of individuals who were employed and reported positive wages, were paid by the hour, and did not have imputed wage rates in both of their outgoing rotation groups, and who earned within $\$ 0.25$ of the state effective minimum wage in their first rotation. $* * * \mathrm{p}<0.01, * * \mathrm{p}<0.05, * \mathrm{p}<0.1$ 


\section{Table A6: Summary Statistics for Individuals Earning Within \$0.25 of the Minimum Wage in Their First}

Rotation, Employed in Both Rotations

(1)

No Minimum Wage Increase

Sample

Year of first outgoing rotation

Variable

Increased wage from first outgoing rotation

Decreased wage from first outgoing rotation

Same wage as first outgoing rotation

Increased real wage from first rotation

Decreased real wage from first rotation

Same real wage as first outgoing rotation

Share of months in sample employed

1-year change in hourly wage (2019)

Size of hourly wage increase (\$)

Size of real wage increase (2019\$)

1 -year change in effective minimum wage (\$)

1-year change in FHFA house price index

1 -year change in state per capita income (\$)

1-year change in state mid-skill employment

1 -year change in state prime-age employment

Education increase

Covered by union in first outgoing rotation

3 -year change in FHFA house price index

3 -year change in state per capita income (\$)

3 -year change in state mid-skill employment

3 -year change in state prime-age employment

Changed 1-digit occupation

Changed 1-digit industry

Changed 2-digit occupation

Changed 2-digit industry

Changed 3-digit occupation

Changed 3-digit industry

2010-2012

0.650

0.106

0.244

0.614

0.386

0

0.923

1.059

1.786

1.933

0

0.153

1560.9

0.00283

0.00360

0.297

0.0294

$-23.11$

4074.8

$-0.0235$

$-0.0193$

0.335

0.227

0.463

0.341

0.524

0.353
Between CPS ORG Rotations

2,513

Observations

Notes: This table reports summary statistics for two sample groups regarding the changes in key labor market indicators between rounds 4 and 8 of the CPS. Columns 1 and 2 display variable means for individuals living in states with no minimum wage increases between rotations and columns 3 and 4 display means for individuals living in states with at least one increase in the minimum wage between outgoing rotations. Columns 1 and 3 include all individuals who were in their first outgoing rotation group from 2010-2012 and columns 2 and 4 include all individuals who were in their first outgoing rotation group from 2013-2018. The sample is from the CPS Outgoing Rotation Groups and consists of individuals who were employed, reported positive wages, were paid by the hour, and did not have imputed wage rates in both of their outgoing rotations, and who earned within $\$ 0.25$ of the effective minimum wage in their first rotation.
(3)

(4)

Minimum Wage Increase Between CPS ORG Rotations

2010-2012 2013-2018

$\begin{array}{cc}0.796 & 0.838 \\ 0.116 & 0.0592 \\ 0.0872 & 0.103 \\ 0.671 & 0.811 \\ 0.329 & 0.189 \\ 0 & 0 \\ 0.924 & 0.930\end{array}$

$0.922 \quad 1.777$

$1.290 \quad 2.212$

2.261

0.547

28.48

2278.7

0.0107

0.00789

0.260

0.0538

80.56

$\begin{array}{rr}3366.1 & 6090.9 \\ -0.0303 & 0.0360\end{array}$

$-0.0230 \quad 0.0225$

$0.246 \quad 0.260$

$0.452 \quad 0.479$

$0.338 \quad 0.376$

$0.519 \quad 0.535$

0.351

0.387

2.213
$0.302 \quad 0.376$ 

Table A7: Summary Statistics for Individuals Earning Within $\$ 0.05$ of the Minimum Wage in
Their First Rotation, Employed in Both Rotations

\begin{tabular}{|c|c|c|c|c|}
\hline \multirow{2}{*}{$\begin{array}{l}\text { Sample } \\
\text { Year of first outgoing rotation }\end{array}$} & \multicolumn{2}{|c|}{$\begin{array}{l}(1) \\
\text { Workers Living in States that } \\
\text { Never Increased Minimum } \\
\text { Wage, 2010-2019 }\end{array}$} & \multicolumn{2}{|c|}{$\begin{array}{l}\text { (3) } \\
\text { Workers Living in States that } \\
\text { Increased the Minimum Wage } \\
\text { at Least Once, 2010-2019 }\end{array}$} \\
\hline & 2010-2012 & 2013-2018 & 2010-2012 & 2013-2018 \\
\hline \multicolumn{5}{|l|}{ Variable } \\
\hline Increased wage from first outgoing rotation & 0.613 & 0.713 & 0.660 & 0.802 \\
\hline Decreased wage from first outgoing rotation & 0.0757 & 0.0426 & 0.0652 & 0.0528 \\
\hline Same wage as first outgoing rotation & 0.312 & 0.244 & 0.275 & 0.145 \\
\hline Share of months in sample employed & 0.905 & 0.913 & 0.925 & 0.929 \\
\hline 1-year change in hourly wage $(\$)$ & 1.008 & 1.562 & 0.976 & 1.618 \\
\hline Size of wage increase $(\$)$ & 1.863 & 2.337 & 1.568 & 2.114 \\
\hline 1-year change in effective minimum wage (\$) & 0 & 0 & 0.0384 & 0.477 \\
\hline 1-year change in FHFA house price index & -0.611 & 14.74 & 1.342 & 30.17 \\
\hline 1-year change in state per capita income & 1615.2 & 1521.9 & 1496.0 & 2340.0 \\
\hline 1-year change in state mid-skill employment & 0.00380 & 0.00745 & 0.00384 & 0.0104 \\
\hline 1-year change in state prime-age employment & 0.00281 & 0.00524 & 0.00464 & 0.00736 \\
\hline Education increase & 0.327 & 0.401 & 0.247 & 0.252 \\
\hline Covered by union in first outgoing rotation & 0.0155 & 0.0115 & 0.0285 & 0.0474 \\
\hline 3-year change in FHFA house price index & -12.80 & 35.40 & -33.63 & 84.43 \\
\hline 3 -year change in state per capita income $(\$)$ & 3904.5 & 3962.1 & 4133.6 & 6261.8 \\
\hline 3-year change in state mid-skill employment & -0.0164 & 0.0143 & -0.0292 & 0.0354 \\
\hline 3-year change in state prime-age employment & -0.0150 & 0.0116 & -0.0222 & 0.0207 \\
\hline Changed 1-digit occupation & 0.346 & 0.379 & 0.316 & 0.344 \\
\hline Changed 1-digit industry & 0.222 & 0.292 & 0.236 & 0.248 \\
\hline Changed 2-digit occupation & 0.487 & 0.497 & 0.434 & 0.457 \\
\hline Changed 2-digit industry & 0.351 & 0.397 & 0.334 & 0.358 \\
\hline Changed 3-digit occupation & 0.537 & 0.557 & 0.492 & 0.512 \\
\hline Changed 3-digit industry & 0.363 & 0.403 & 0.352 & 0.368 \\
\hline Observations & 581 & 610 & 981 & 1,837 \\
\hline
\end{tabular}

Notes: This table reports summary statistics for two sample groups regarding the changes in key labor market indicators between rounds 4 and 8 of the CPS. Columns 1 and 2 display variable means for individuals living in states with no minimum wage increases between 2010 and 2019 and columns 3 and 4 display means for individuals living in states with an increase in the minimum wage between 2010 and 2019. Columns 1 and 3 include all individuals who were in their first outgoing rotation group from 2010-2012 and columns 2 and 4 include all individuals who were in their first outgoing rotation group from 2013-2018. The sample is from the CPS Outgoing Rotation Groups and consists of individuals who were employed, reported positive wages, were paid by the hour, did not have imputed wage rates in both of their outgoing rotations, and earned within $\$ 0.05$ of the effective minimum wage in their first rotation. 


\section{Table A8: Correlations Between Changes in Reported Hourly Wage and Macroeconomic Indicators for Individuals Employed in Both Rotations and Earning Within \$0.05 of the Effective Minimum Wage in Their First Rotation}

\section{Variable}

State ever had minimum wage change from 2010-2019

State had minimum wage increase between rotations

Year 2013-2018

Share of months in sample employed

1 -year change in effective minimum wage (\$)

1 -year change in FHFA house price index

1 -year change in state per capita income

1 -year change in state mid-skill employment

1 -year change in state prime-age employment

Education increase

Covered by union in first outgoing rotation

3 -year change in FHFA house price index

3-year change in state per capita income (\$)

3 -year change in state mid-skill employment

3 -year change in state prime-age employment

Changed 1-digit occupation

Changed 1-digit industry

Changed 2-digit occupation

Changed 2-digit industry

Changed 3-digit occupation

Changed 3-digit industry
0.0124

$0.0618 * * *$

$0.0791 * * *$

$-0.0000206$

$0.0841 * * *$

$0.0756^{* * *}$

$0.0350 *$

0.0289

$-0.0301$

$-0.00689$

0.0270

$0.0911 * * *$

$0.0615^{* * *}$

$0.0668 * * *$

0.0449*

$0.102 * * *$

$0.131 * * *$

$0.0974 * * *$

$0.134 * * *$

$0.0849 * * *$

$0.133 * * *$

Observations

4,009

This table displays bivariate correlations between the change in reported hourly wages between outgoing rotations for individuals in the Current Population Survey and changes in other key macroeconomic and individual indicators. The sample is from the CPS Outgoing Rotation Groups and consists of individuals who were employed and reported positive wages, were paid by the hour, and did not have imputed wage rates in both of their outgoing rotation groups and who earned within $\$ 0.05$ of the effective minimum wage in their first rotation. $* * * \mathrm{p}<0.01, * * \mathrm{p}<0.05, * \mathrm{p}<0.1$ 


\section{Table A9: Summary Statistics for Individuals Earning Within $\$ 0.05$ of the Minimum Wage in Their First Rotation, Employed in Both Rotations}

(1)

2010-2012 2013-2018

No Minimum Wage Increase Between CPS ORG Rotations
(3)

2010-2012 2013-2018

Minimum Wage Increase Between CPS ORG Rotations
Sample

Variable

Increased wage from first outgoing rotation

Decreased wage from first outgoing rotation

Same wage as first outgoing rotation

Share of months in sample employed

1 -year change in hourly wage (\$)

Size of hourly wage increase (\$)

1-year change in effective minimum wage (\$)

1-year change in FHFA house price index

1-year change in state per capita income

1-year change in state mid-skill employment

1-year change in state prime-age employment

Education increase

Covered by union in first outgoing rotation

3 -year change in FHFA house price index

3-year change in state per capita income (\$)

3 -year change in state mid-skill employment

3 -year change in state prime-age employment

Changed 1-digit occupation

Changed 1-digit industry

Changed 2-digit occupation

Changed 2-digit industry

Changed 3-digit occupation

Changed 3-digit industry

Observations

Notes: This table reports summary statistics for two sample groups regarding the changes in key labor market indicators between rounds 4 and 8 of the CPS. Columns 1 and 2 display variable means for individuals living in states with no minimum wage increases between rotations and columns 3 and 4 display means for individuals living in states with at least one increase in the minimum wage between outgoing rotations. Columns 1 and 3 include all individuals who were in their first outgoing rotation group from 2010-2012 and columns 2 and 4 include all individuals who were in their first outgoing rotation group from 2013-2018. The sample is from the CPS Outgoing Rotation Groups and consists of individuals who were employed, reported positive wages, were paid by the hour, did not have imputed wage rates in both of their outgoing rotations, and earned within $\$ 0.05$ of the effective minimum wage in their first rotation.
0.859

0.0450

0.0957

0.931

1.742

2.190

0.636

31.70

2405.4

0.0112

0.00745

0.235

0.0500

92.17

6664.1

0.0396

0.0258

0.355

0.255

0.463

$\begin{array}{llll}0.343 & 0.367 & 0.327 & 0.368\end{array}$

$\begin{array}{llll}0.508 & 0.532 & 0.517 & 0.516\end{array}$

0.358

0.373

0.380

1,379

